\title{
The categorical perception of colors and facial expressions: The effect of verbal interference
}

\author{
DEBI ROBERSON and JULES DAVIDOFF \\ Goldsmiths College, University of London, London, England
}

\begin{abstract}
A series of five experiments examined the categorical perception previously found for color and facial expressions. Using a two-alternative forced-choice recognition memory paradigm, it was found that verbal interference selectively removed the defining feature of categorical perception. Under verbal interference, there was no longer the greater accuracy normally observed for cross-category judgments relative to within-category judgments. The advantage for cross-category comparisons in memory appeared to derive from verbal coding both at encoding and at storage. It thus appears that while both visual and verbal codes may be employed in the recognition memory for colors and facial expressions, subjects only made use of verbal coding when demonstrating categorical perception.
\end{abstract}

The complex relationship between language and mental representations of the visual world is evident from our attempts to describe objects. Our use of nouns (and adjectives) is essentially categorical rather than a reference to one particular object. For example, the words $d o g$ and table are appropriate for vast numbers of clearly perceptually different dogs or tables, and the word red stands for an equally large set of discriminably different colors. The particular dogs, tables, or shades of red that make up a category are not organized at random within the category, and it is of considerable current interest to ask about the internal organization of such categories (Goldstone, 1994). The present paper concerns the organization of category types considered as perceptual rather than conceptual (e.g., phonemes, colors, and facial expressions) and the relationship of the underlying categorical representations to verbal coding. It makes use of properties of categories concerned with effects at category boundaries; these effects derive from what is known as categorical perception (Bornstein \& Korda, 1984; Harnad, 1987). Categorical perception will be demonstrated by the superior recognition of items given a choice from cross-category pairs of stimuli as opposed to a choice from within-category pairs.

Categorical perception clearly requires another process in addition to discrimination ability (Harnad, 1987). However, no detailed investigations have been undertaken to consider the type of coding underlying the phenomenon of categorical perception. The reason for the lack of

D.R. was supported by ESRC Grant R000236750. The computer programs for Experiments 2-5 were created by Emre Ozgen and Michael Pilling of the University of Surrey. We thank Andy Young and an anonymous reviewer in the preparation of the manuscript. Andy Young kindly provided the original stimuli for Experiment 5. Correspondence should be addressed to J. Davidoff, Department of Psychology, Goldsmiths College, University of London, New Cross, London SE14 6NW, U.K. (e-mail: j.davidoff@gold.ac.uk). research may be the assumption that the coding that underlies categorical perception is visual. Thus, the present set of experiments arose from attempts to investigate the specificity of the visual coding that could be the basis for categorical perception by the use of visual interference inserted between target and test stimuli. However, control conditions of verbal interference produced surprising results, and these were investigated at greater length.

The series of experiments made use of a previous investigation that established the category boundary between blue and green (Roberson, Davidoff, \& Braisby, 1999). In Roberson et al., we made use of a task introduced by Etcoff and Magee (1992). In their procedure, three stimuli were presented in sequence. In our adaptation, a target stimulus was followed by the simultaneous presentation of a two-alternative forced choice (2-AFC). One of the two stimuli was identical to the target. Our procedure reduces the memory load for the subject and avoids problems of response bias that posed a concern in the original procedure (Young et al., 1997).

\section{EXPERIMENT 1 \\ Effect of Visual and Verbal Interference on Categorical Perception of Color}

The original intention of this experiment was to investigate the basis of the presumed visual coding implicated in categorical perception. To that end a comparison was made between a blank interval and one filled with colored stimuli in a 2-AFC. However, since artifacts of verbal interference had been ruled out as a possible cause of cross-category advantages in the 2-AFC procedure (Young et al., 1997), a condition was added in which the interval was filled with the recitation of color names. Two delay intervals were used ( 5 and $10 \mathrm{sec}$ ) because Brown and Lenneberg (1954) suggested that pictorial coding of a colored stimulus lasts for around $7 \mathrm{sec}$, and so different 
Table 1

Targets and Test Pairs Within

and Cross Category in Experiment 1

\begin{tabular}{ccccc}
\hline \multicolumn{2}{c}{ Within Category } & & \multicolumn{2}{c}{ Cross Category } \\
\cline { 1 - 2 } \cline { 4 - 5 } One step & Two step & & One step & Two step \\
\hline 5 B-2.5 B & 5 B-10 BG & & 10 BG-7.5 BG & 2.5 B-7.5 BG \\
$2.5 \mathrm{BG}-10 \mathrm{G}$ & $5 \mathrm{BG}-10 \mathrm{G}$ & & $7.5 \mathrm{BG}-5 \mathrm{BG}$ & $10 \mathrm{BG}-5 \mathrm{BG}$ \\
\hline
\end{tabular}

effects of verbal coding might be expected from the two delay conditions.

\section{Method}

Subjects. Forty-eight subjects took part in this experiment; 24 in the 5-sec delay condition and 24 in the 10-sec delay condition. All were undergraduates at Essex University. Some were 1st-year psychology students taking part for course credit and some were paid for their participation. A further 24 subjects from the same pool took part in a baseline condition with a brief $(300-\mathrm{msec})$ interval between target and test stimuli. Approximately equal numbers of males and females took part, and ages ranged from 18 to 49 years. All subjects were screened for color vision using the short version of the Ishihara (1992) test for color blindness.

Stimuli. Seven stimuli were taken from Munsell samples at equal lightness and saturation that straddled the blue/green boundary previously estimated in Roberson et al. (1999). A further pilot experiment confirmed that the blue/green boundary was at approximately 7.5 BG (see also Bornstein \& Korda, 1984).

Target stimuli were mounted in the center of white cards for use in the automatic card changers of an Electronic Developments tachistoscope. Test stimuli were mounted side by side at equal distance from the fixation point and separated by a distance of $2.2 \mathrm{~cm}$ Stimuli subtended a visual angle of $2.10^{\circ} \times 2.10^{\circ}$ on a white field $13.1^{\circ} \times 9.0^{\circ}$. Test stimuli were made up of pairs of stimuli that were either one or two Munsell steps apart and were either within or across the category boundary. Table 1 shows the list of test pairs. The boundary chip ( $7.5 \mathrm{BG}$ ) was included in cross-category pairs because of the limitations in the commercially available Munsell samples.

Visual interference was provided by presentation of a multicolored dot pattern (one of the nonverbal plates of the 1992 Ishihara test for color blindness) mounted on cards and presented in the third field of the tachistoscope. Verbal interference was a list of nonbasic color words (by the criteria set out in Berlin \& Kay, 1969) frequently used to describe desaturated colors. In a pilot experiment using 12 subjects, all of these color words were unanimously rated inappropriate to describe any of the blue and green stimuli in this experiment. Examples of the words used are beige, fawn, tan, olive, mauve, and khaki. All were typed in uppercase 12-point Times regular font and mounted on a $10 \times 15 \mathrm{~cm}$ card for presentation in the third field of the tachistoscope. The layout of interference stimuli can be found in Appendix A. Both types of interference stimuli subtended a visual angle of $13.1^{\circ} \times 9.0^{\circ}$.

Procedure. Stimuli were presented binocularly in a three-field tachistoscope at approximately $60 \mathrm{~cm}$ from the observers' eyes and illuminated by artificial daylight $(\sim 6200 \mathrm{~K})$. Subjects were instructed that they would see first a target stimulus followed by two test stimuli side by side from which they had to select the one matching the target stimulus. There was a delay of either 5 or $10 \mathrm{sec}$ between target and test stimuli. During the 5- or $10-\mathrm{sec}$ interval, subjects saw a blank white card, the visual interference (instructions were to track the line through the dot pattern with their eyes), or the verbal interference (instructions were to read the words aloud). Order of presentation of the three interference conditions (none, visual, and verbal) was counterbalanced across subjects with an interval of $1 \mathrm{~min}$ between conditions. Subjects in the baseline condition had a brief $(300-\mathrm{msec})$ interval between target and test stimuli with, of course, no interference in that interval.

Targets and test pairs for each trial were presented for $1 \mathrm{sec}$ each with a $5-\mathrm{sec}$ interval between trials. Each pair was tested twice, once with each member as target, making a total of 16 trials of which 8 were within category and 8 cross category in each condition. Subjects were instructed to press the left key if the stimulus on the left matched the target and the right key if the stimulus on the right matched the target. Position of targets within test pairs was balanced so that equal numbers of left and right responses were required. Subjects were not instructed to make speeded responses. Subjects were given two practice trials before the start of the experiment.

\section{Results}

For the baseline condition, correct recognition scores were analyzed using a 2 (pair type: cross vs. within) $\times 2$ (step: 1 vs. 2 ) analysis of variance (ANOVA), with repeated measures over both factors. The results showed that targets were better recognized in cross-category pairs than in within-category pairs $\left[F(1,23)=21.30, M S_{\mathrm{e}}=.440\right.$, $p<.001]$ and a significant effect of step size $[F(1,23)=$ $\left.8.46, M S_{\mathrm{e}}=.493, p<.01\right]$. Pairs separated by two Munsell steps were consistently differentiated more accurately than those separated by only one step, a result also found by Bornstein and Korda (1984). There was no significant interaction $(F<1)$. Thus, our baseline condition showed that subjects perceived these colored stimuli in a categorical fashion.

For the delay conditions, the data were analyzed in a 2 (delay: 5 vs. $10 \mathrm{sec}$ ) $\times 3$ (interference type: none vs. visual vs. verbal) $\times 2$ (category type: cross vs. within) ANOVA, with repeated measures over the last two factors. There was no effect of delay $\left[F(1,46)=2.38, M S_{\mathrm{e}}=2.22\right.$, $p>.1]$, but there were significant main effects of interference type $\left[F(2,92)=14.40, M S_{\mathrm{e}}=1.57, p<.01\right]$ and category type $\left[F(1,46)=34.09, M S_{\mathrm{e}}=1.07, p<.01\right]$. In addition, there was a significant interaction between interference type and category type $\left[F(2,92)=6.93, M S_{\mathrm{e}}=\right.$ $1.07, p<.01$; Figure 1], but all other two-way interactions and the three-way interaction yielded $F \mathrm{~s}<1$.

Analysis of the interaction by Newman-Keuls showed that, for cross-category stimuli, performance was better with no interference than with either visual or verbal interference (both $p \mathrm{~s}<.01$ ). For within-category stimuli, visual interference resulted in poorer performance than with either no or verbal interference (both $p s<.01$ ). Comparing the effects of interference between category types, it was found that targets in cross-category pairs were better recognized than those in within-category pairs under no interference and the visual interference conditions (both $p s<.01$ ), but there was no significant difference between category type under verbal interference.

\section{Discussion}

A superiority for recognition from cross-category pairs was observed in all conditions except that with verbal interference. The result probably underestimates the extent of the advantage. We know that the boundary for 


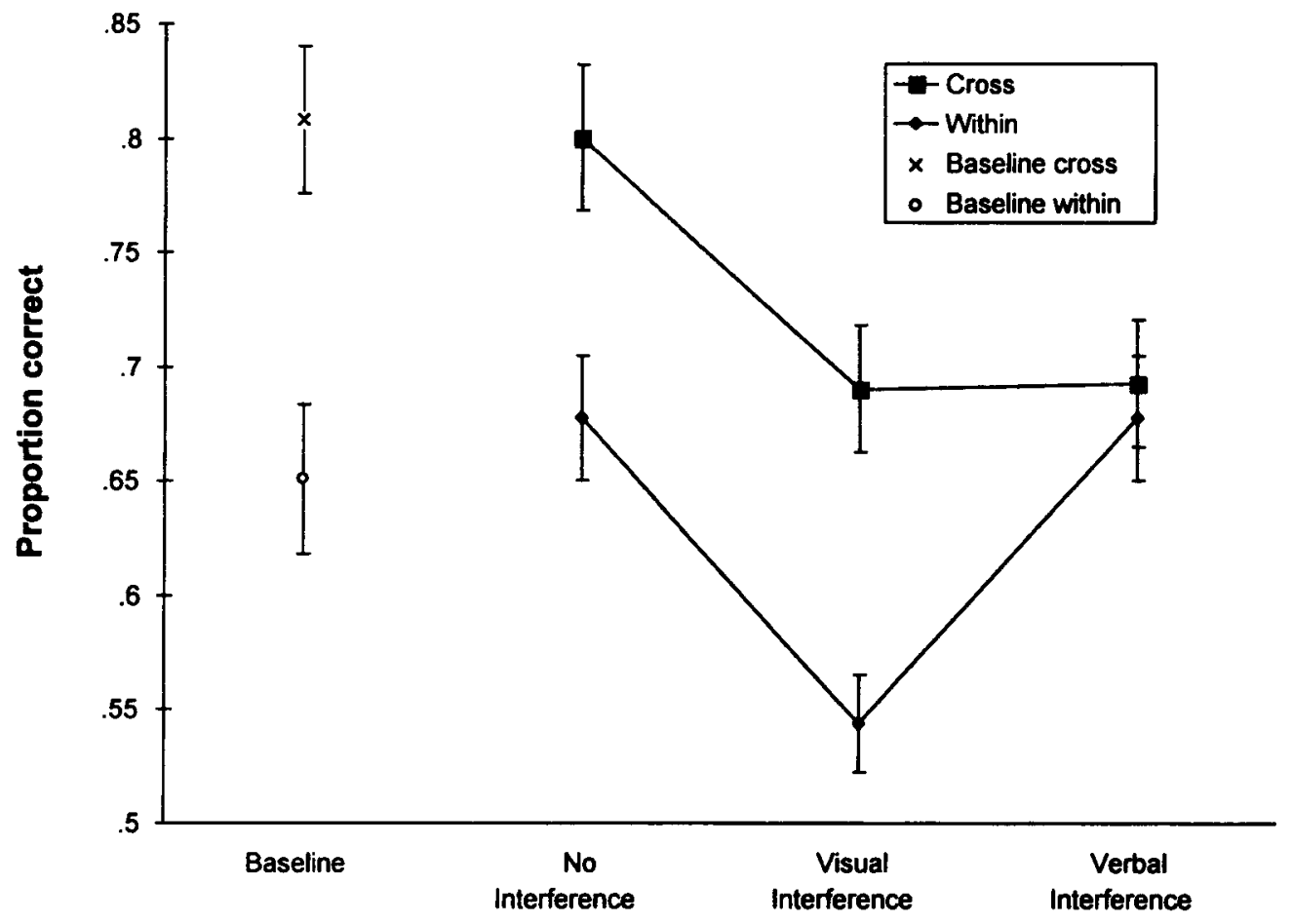

Figure 1. Mean proportion of correct identifications in Experiment 1 for cross- versus within-category pairs of colors with no, visual, or verbal interference.

each subject is within the range of our one-step crosscategory pairs (Roberson et al., 1999), but having to use the boundary chip for both pairs meant that one of the one-step cross-category pairs would, in fact, be within category. Thus, our result here must be considered a conservative estimate of the magnitude of the cross-category advantage.

Both visual and verbal interference produced some deterioration in performance; this would suggest that both visual and verbal coding is employed in the recognition memory task. However, while visual interference produced an equal amount of decrement in performance for cross- and within-category pairs, verbal interference did not. Verbal interference produced approximately the same decrement as visual interference in performance for cross-category pairs but almost no decrement for withincategory pairs. Thus, the categorical advantage appears not to arise from visual coding. Furthermore, delay did not interact with interference type, thus not supporting the claim that verbal coding would be more likely employed at the 10-sec delay than with a 5-sec delay condition (Brown \& Lenneberg, 1954). Our data imply that the cross-category advantage was solely due to verbal coding: this was a surprise and our first response was to replicate the result. We thought it just possible that the presentation of stimuli in a tachistoscope might somehow have made subjects more prone to code stimuli verbally. So Experiment 2 replicated the stimuli on a computer monitor.

\section{EXPERIMENT 2 Effect of Verbal Interference on Categorical Perception Using Computerized Displays (Colors)}

Experiment 2 sought to replicate the effects of verbal interference found in Experiment 1 but with computergenerated Munsell colors. Stimuli were matched by their $C^{*} I^{*} E^{*}$ coordinates and the simulation confirmed by repeating the naming experiment of Roberson et al. (1999). The position of the boundary at 7.5 BG was confirmed both by naming consensus and by speed of naming.

\section{Method}

Subjects. Twenty-two subjects from the subject pool at Surrey University were paid for their participation. All were screened for color vision using the City University Colour Vision Test (Fletcher, 1980). Approximately equal numbers of males and females took part. Ages ranged from 17 to 46 years.

Apparatus and Stimuli. The use of computerized stimuli allowed the creation of stimuli between the available Munsell steps. These new stimuli were created by locating the midpoint between each pair of Munsell stimuli along each of the $C^{*} I^{*} E^{*}$ coordinates. In addition to the screen matches of the seven Munsell stimuli used in Experiment 1, we created an additional five intermediate steps. The full set of 12 stimuli can be found in Appendix B.

Target and test stimuli were displayed on a Sony Trinitron Multiscan screen in the center of a gray background. Samples each subtended a visual angle of $2.10^{\circ} \times 2.10^{\circ}$ on a white field. Verbal interference consisted of the same set of words as used in Experiment 1. 
Table 2

Targets and Test Pairs Within and Cross Category in Experiment 2

\begin{tabular}{|c|c|c|c|}
\hline \multicolumn{2}{|c|}{ Within Category } & \multicolumn{2}{|c|}{ Cross Category } \\
\hline One step & Two step & One step & Two step \\
\hline $\begin{array}{l}3.75 \mathrm{~B}-1.25 \mathrm{~B} \\
3.75 \mathrm{BG}-1.25 \mathrm{BG}\end{array}$ & $\begin{array}{l}7.5 \mathrm{~B}-2.5 \mathrm{~B} \\
2.5 \mathrm{BG}-7.5 \mathrm{G}\end{array}$ & $8.75 \mathrm{BG}-6.25 \mathrm{BG}$ & $10 \mathrm{BG}-5 \mathrm{BG}$ \\
\hline
\end{tabular}

The lists of words appeared in the center of a gray screen. Visual interference consisted of one of the nonverbal plates of the Ishihara (1992) test for color blindness also presented in the center of a gray screen. Both types of interference stimuli subtended a visual angle of $13.1^{\circ} \times 13.1^{\circ}$.

\section{Procedure}

Table 2 shows the composition of the pairs of stimuli tested in Experiment 2.

Subjects saw each test pair eight times in each of three (verbal interference vs. visual interference vs. no interference) conditions, four times with each member of the pair as target. Position of the target within the pair was counterbalanced and the order of presentation within blocks was randomized. Each condition was split into two blocks and the order of presentation of the blocks was randomized. The other aspects of the procedure were identical to that of Experiment 1 except for a few points. The delay between target and test pairs was always at $5 \mathrm{sec}$. Also, subjects were asked to use left and right mouse buttons as response keys. Four practice trials in each condition were given to familiarize subjects with the key procedure and these were carried out in darkness to give subjects time to adapt to dark conditions. At the end of the practice period, the experiment was carried out in a darkened laboratory with the only light source being the computer monitor.

\section{Results}

The proportion of correct scores for each subject was analyzed in a 3 (interference type: none vs. visual vs. verbal) $\times 2$ (pair type: cross vs. within) ANOVA with repeated measures over both factors. There was a significant main effect of interference type $[F(2,42)=9.21$, $\left.M S_{\mathrm{e}}=.01, p<.001\right]$ and category type $[F(1,21)=14.61$, $M S_{\mathrm{e}}=.01, p<.001 ;$ Figure 2]. The interaction was also significant $\left[F(2,42)=3.33, M S_{\mathrm{e}}=.01, p<.05\right]$.

Analysis of the interaction in Newman-Keuls pairwise comparisons showed, for cross-category pairs, that performance with verbal interference was significantly worse than that for either none or visual interference (both $p \mathrm{~s}<$ $.01)$; there was no difference between interference types for within-category pairs. Targets in cross-category pairs were better recognized than those in within-category pairs with no interference $(p<.05)$ and those with visual interference $(p<.01)$, but not those with verbal interference.

\section{Discussion}

This experiment, using our new computer-generated stimuli, produced results very similar to those found in Experiment 1 . Without interference, cross-category discriminations were easier than within-category discriminations. However, verbal interference destroyed the advantage in recognition memory for stimuli crossing the category boundary.

The only important difference in results between Experiments 1 and 2 concerned the effect of visual inter- ference. In Experiment 1, visual interference caused a significant deterioration in performance for both crosscategory and within-category pairs; no such deterioration was found in Experiment 2. Several possible differences between the experimental conditions of the two experiments might account for this difference. Contrast levels were higher and the size of display slightly larger on the screen-generated Ishihara plate; this could have made the visual tracking task easier since in the on-screen version the visual interference appeared against a gray background to reduce light from the screen. Thus, Experiment 2 reveals little about the role of visual coding in categorical perception. However, the crucial finding from Experiment 2 is that, once again, verbal interference removed the advantage for cross- over within-category pairs. The question of the specificity of verbal interference was addressed in Experiment 3.

\section{EXPERIMENT 3 \\ Effect of Varying the Type of Verbal Interference on Categorical Perception Using Both Color and Noncolor Words}

The finding that verbal interference selectively removes the superior recognition of cross-category items implies that this advantage arises as a result of verbal coding. The specificity of the interference would inform us about whether the resources that preserve the verbal code are specific to color names or rely on a general resource such as that of a unitary supervisory system directing attention to a variety of tasks (Bourke, Duncan, $\&$ Nimmo-Smith, 1996). Given a unitary resource, reading aloud would interfere with color name recall to the extent that overall processing capacity is exceeded. In this case, the relatedness of the interference material to color names should not affect the extent of the advantage found for cross-category items. While it is beyond the scope of this set of experiments to fully investigate the allocation of attentional resources, Experiment 3 asked whether the effects of verbal interference were restricted to color words or would appear with any type of verbal interference. A set of non-color-related words were chosen, matched for word length and frequency to the words used in Experiments 1 and 2 (Carroll, Davies, \& Richman, 1971) and the critical verbal interference condition was repeated.

\section{Method}

Subjects. Twenty-one subjects from the subject pool at Surrey University took part in the experiment for course credit. All were screened for color vision using the City University Colour Vision Test (Fletcher, 1980). Approximately equal numbers of males and females took part. Ages ranged from 18 to 35 years. No subjects had taken part in any previous experiments.

Apparatus and Stimuli. The same apparatus and color stimuli were used as in Experiment 2. Color word verbal interference also consisted of the same set of words as used in Experiment 2. Noncolor word interference consisted of the set of words listed in Appendix C. The lists of words appeared in the center of a gray screen.

Procedure. Subjects saw each test pair eight times in each of three (color word verbal interference vs. noncolor word verbal in- 


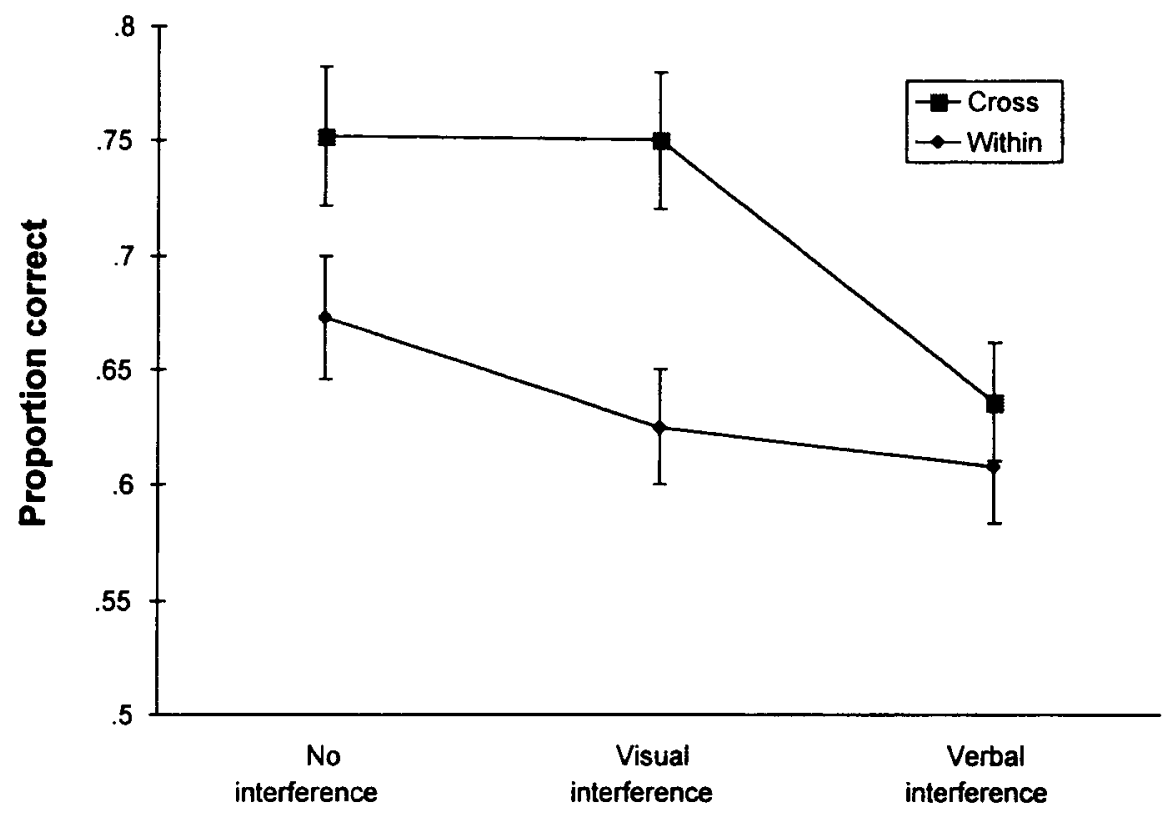

Figure 2. Mean proportion of correct recognitions for different types of category pairs with no, visual, or verbal interference in Experiment 2. Error bars represent the standard errors of the mean.

terference vs. no interference) conditions, four times with each member of the pair as target. Position of the target within the pair was counterbalanced and the order within blocks was randomized. The other aspects of the procedure were identical to that of Experiment 2.

\section{Results and Discussion}

Figure 3 shows the mean proportion of correct scores in each of the three interference conditions. The proportion of correct scores in each condition was examined in a 3 (interference: none vs. color word vs. noncolor word) $\times 2$ (pair type: cross- vs. within-category) ANOVA with repeated measures over both factors. There was a significant effect of interference $\left[F(2,40)=7.76, M S_{\mathrm{e}}=.09\right.$, $p<.01]$, a significant effect of pair type $[F(1,20)=4.32$, $\left.M S_{\mathrm{e}}=.01, p<.05\right]$, and a significant interaction $[F(2,40)$ $\left.=4.08, M S_{\mathrm{e}}=.01, p<.03\right]$.

Analysis of the interaction in Newman-Keuls pairwise comparisons showed that the difference between crossand within-category pairs was significant without interference $(p<.01)$, but it was not significant either with color word or noncolor word interference. For withincategory pairs, there was no difference between the conditions, but for cross-category pairs, significantly more targets were correctly identified with no interference than either with color word or with noncolor word interference (both $p$ s $<.01$ ).

In Experiments 1 and 2, the verbal interference consisted of color names. It might be argued that interference from the same domain could trigger associated visual representations that could be the true cause of the verbal interference. However, we find no evidence for cross-category advantages regardless of whether or not the words used in the verbal interference are related to color. Thus, the results of Experiment 3 point even more strongly to a verbal basis to the cross-category advantage.

We cannot tell from the design of Experiment 3 at what stage of encoding and rehearsal of a color name the interference has its effect. Visual presentation of the interference task meant that it could only be presented in the retention interval. Therefore, it cannot inform as to whether the disruption occurs to the storage or rehearsal of information about the target item rather than to the encoding of the item. Experiment 4 therefore set out to contrast the effect of verbal interference during encoding with that of the same interference during storage.

\section{EXPERIMENT 4 \\ Effect of Verbal Interference on Categorical Perception at Encoding, During Storage, and Throughout the Experiment}

Experiments 1, 2, and 3 demonstrated the removal of categorical perception effects under verbal interference. The locus of these interference effects could be at either encoding or during storage. In Experiment 4, reading words aloud from the screen was replaced by counting aloud backward; the change in interference permitted a comparison of the effects of interference at encoding versus during storage.

Verbal interference would clearly impede the storage of verbally coded items, but there could also be similar effects at encoding. An effect at encoding could arise because interference alters the balance of available information about to-be-remembered visual items. Recent accounts of the coding of visual items for recognition (Mulligan, 1999) suggest that presentation of a visual 


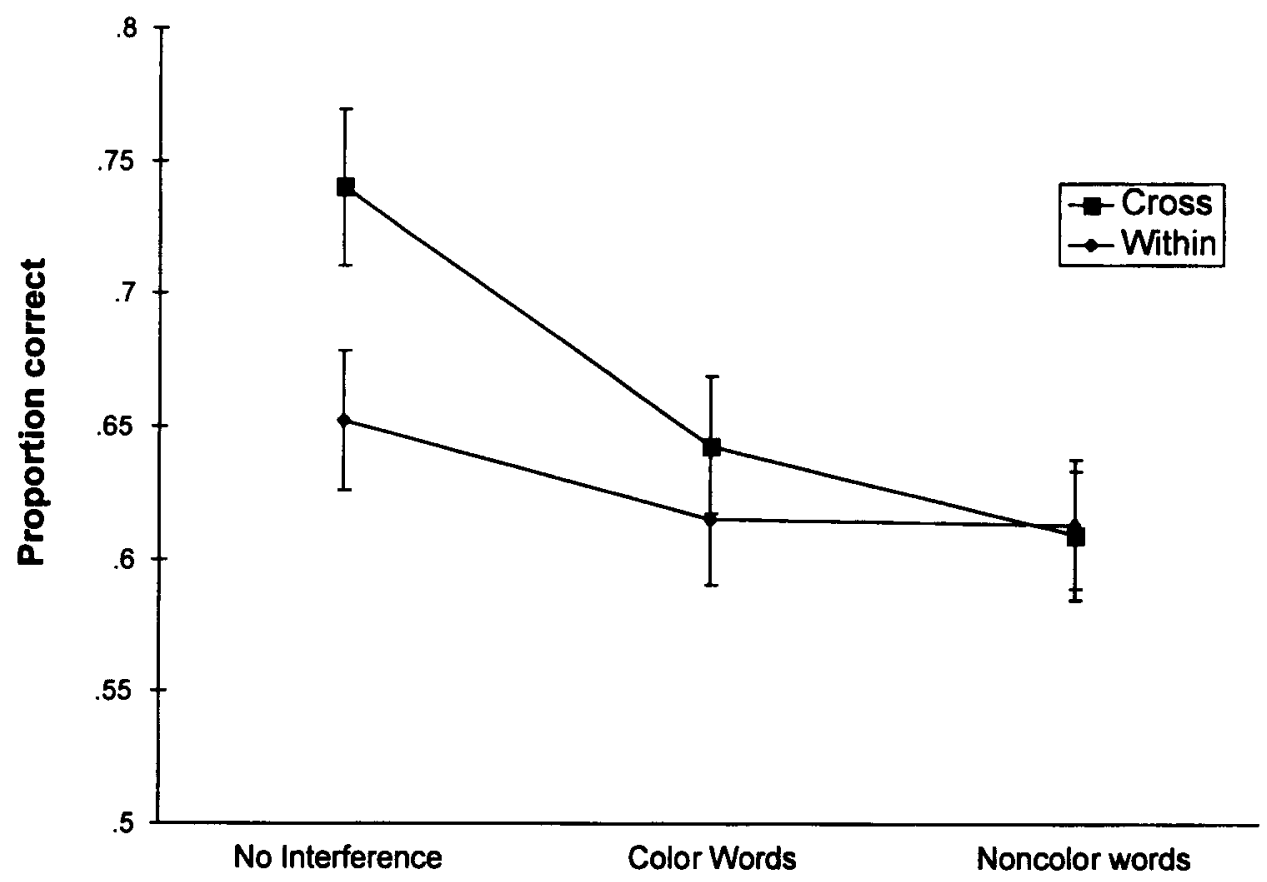

Figure 3. Mean proportion of correct recognitions for different types of category pairs with no, color word, or noncolor word interference in Experiment 3. Error bars represent the standard errors of the mean.

item initiates automatic activation both of a visual trace and of higher order associative information about the item seen (semantic, lexical, phonemic, etc.). Where visual processing is abruptly curtailed, before encoding is completed, the subject could be forced to rely on the residual activation of more lexical information. Thus, Experiment 4 compared the effects of verbal interference at encoding, during storage, and at both these stages in the retrieval process.

\section{Method}

Subjects. Twenty subjects from the subject pool at Surrey University were paid for their participation. All were screened for color vision using the City University Colour Vision Test (Fletcher, 1980). Approximately equal numbers of males and females took part. Ages ranged from 20 to 45 years. No subjects had taken part in any previous experiments.

Apparatus and Stimuli. The same apparatus and pairs of color stimuli were used as in Experiment 3.

Procedure. Subjects carried out the 2-AFC recognition task in four conditions: no interference, interference at encoding only, interference during storage only, and a both condition in which interference occurred throughout the encoding and storage process.

Verbal interference was triggered by the appearance on the screen of a random number between 50 and 99 from which subjects were required to count backward in twos. In the encoding-only condition, subjects were required to start counting backward aloud as soon as they saw a number on the screen and to continue until the target stimulus disappeared. In the storage-only condition, the number appeared after the target and subjects were required to continue counting until the test stimuli appeared. In the both condition, the number appeared before the target stimulus and subjects were required to continue counting backward until the test stimuli appeared. Four practice trials of each condition were given, and this period was also used for dark adaptation of the subjects. Conditions were blocked into two halves and the presentation of the eight blocks was randomized.

\section{Results}

Figure 4 shows the mean proportion of correct scores in each of the four conditions tested. The proportion of correct scores in each condition was examined in a 4 (interference: none vs. encoding vs. storage vs. both $) \times 2$ (pair type: cross- vs. within-category) ANOVA with repeated measures over both factors. There was a significant effect of interference $\left[F(3,57)=33.87, M S_{\mathrm{e}}=.01\right.$, $p<.001]$, a significant effect of pair type $[F(1,19)=$ $\left.6.32, M S_{\mathrm{e}}=.13, p<.03\right]$, and a significant interaction $\left[F(3,57)=3.09, M S_{\mathrm{e}}=.01, p<.05\right]$.

An analysis of the interaction by Newman-Keuls showed that the difference between cross- and withincategory pairs was significant in only the no-interference condition $(p<.01)$. In terms of cross-category pairs, most interference was found in the both condition; this was significantly different from all other conditions (all $p \mathrm{~s}<.01)$. Interference during storage produced more impairment than during encoding or no interference (both $p \mathrm{~s}<.01)$. There was no significant difference between the no-interference condition and interference only during encoding. Regarding within-category pairs, most in- 


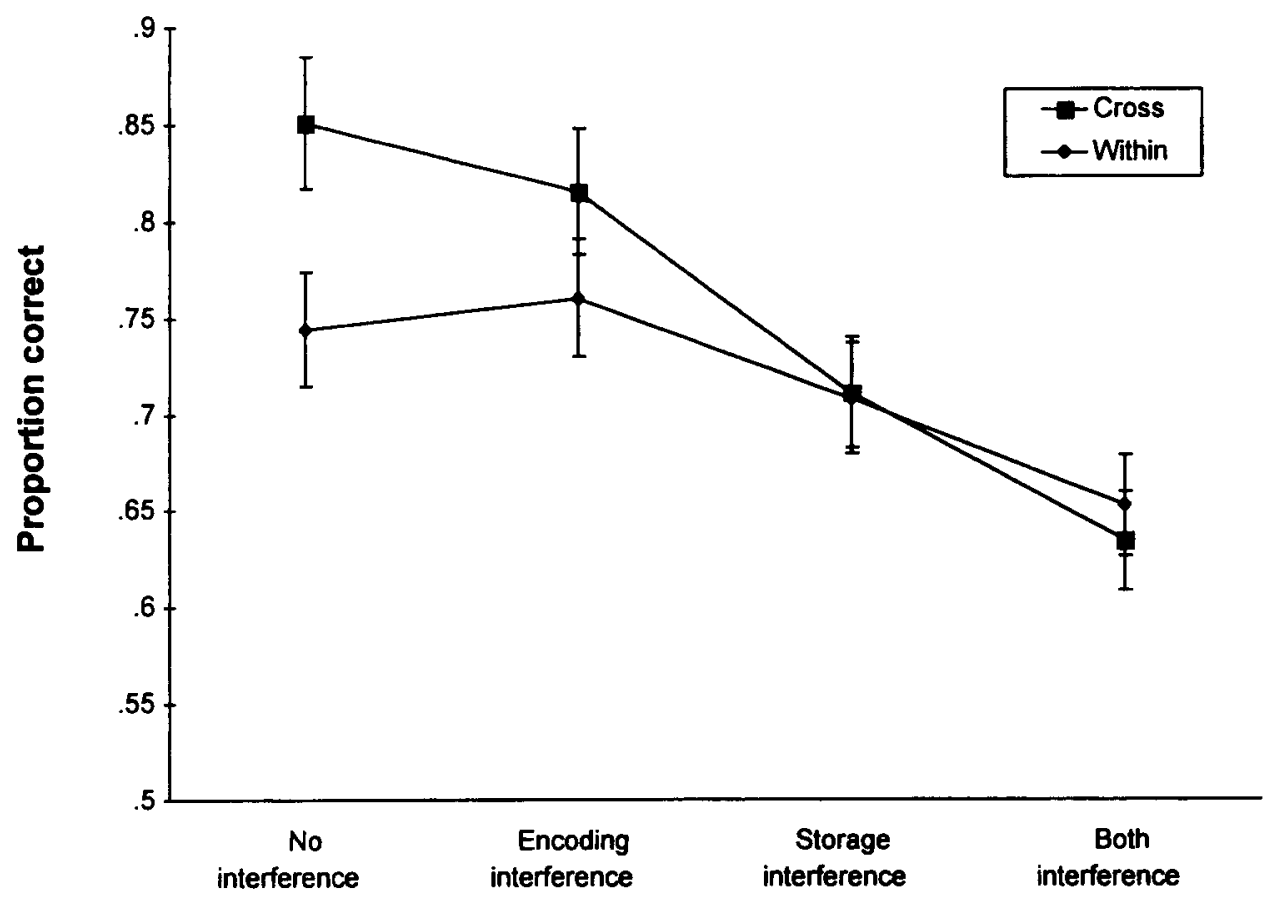

Figure 4. Mean proportion of correct recognitions for different types of category pairs with no interference, interference at encoding, interference during storage, or interference both at encoding and during storage in Experiment 4. Error bars represent the standard errors of the mean.

terference was again found in the both condition; this was again significantly different from all other conditions (all $p \mathrm{~s}<.05$ ), but there were no other differences between conditions. Though the impairment found in the both condition (compared with the storage condition) was greater for cross-category pairs, it did not differ significantly from the same comparison for within-category pairs.

\section{Discussion}

Clearly the longer the interference continued, the greater the cognitive load it placed on subjects. First, in regard to the pattern of performance between nointerference and interference at encoding only, it must be remembered that the duration of the secondary task at encoding was only $1 \mathrm{sec}$. So, while it is not so surprising that verbal interference did not cause a significant decrement in recognition for cross-category pairs, it is of some note that the combined trends are sufficient to remove the advantage for cross-category pairs. We also note that the duration of the delay did not affect subjects' accuracy in recognition memory in Experiment 1 . In fact, in that experiment, performance at the 5- or 10-sec delay with no interference was almost identical to that with no delaya result that would suggest an effect at encoding. However, given the constraints of our paradigm in Experiment 4, it is no surprise that it easier to show the disruption of a verbal code at storage. Verbal interference at this stage did not affect recognition of within-category pairs but dramatically reduced performance for cross-category pairs.

\section{EXPERIMENT 5 \\ Effect of Visual and Verbal Interference on Categorical Perception (Facial Expression)}

Experiments 1-4 have shown quite clearly that verbal interference will remove the cross-category advantage that might have otherwise been presumed to arise from aspects of visual coding. These experiments concerned color categories; we naturally wished to inquire whether other forms of categorical perception could be similarly disrupted by verbal interference. Following the evidence in favor of categorical perception in Calder, Young, Perrett, Etcoff, and Rowland (1996), we considered the question by using a set of stimuli (happy-fearful-angry) taken from their experiment.

A pilot study using scanned versions from the published material (Calder et al., 1996) produced results that again demonstrated that the recognition advantage for cross-category pairs is removed by verbal interference. In Experiment 5, we were able to use the original computerized images to verify these preliminary results.

\section{Method}

Subjects. Twenty-four paid subjects (males and females ranging in age between 17 and 43 years) from the subject pools at Surrey University and at Goldsmiths' College took part in Experiment 5.

Stimuli. Taking the stimuli used in Calder et al. (1996), pairs were constructed to be either within category or cross category with respect to their facial expression. Pilot studies were carried out using one-, two-, and three-step pairs; one-step pairs were found to 


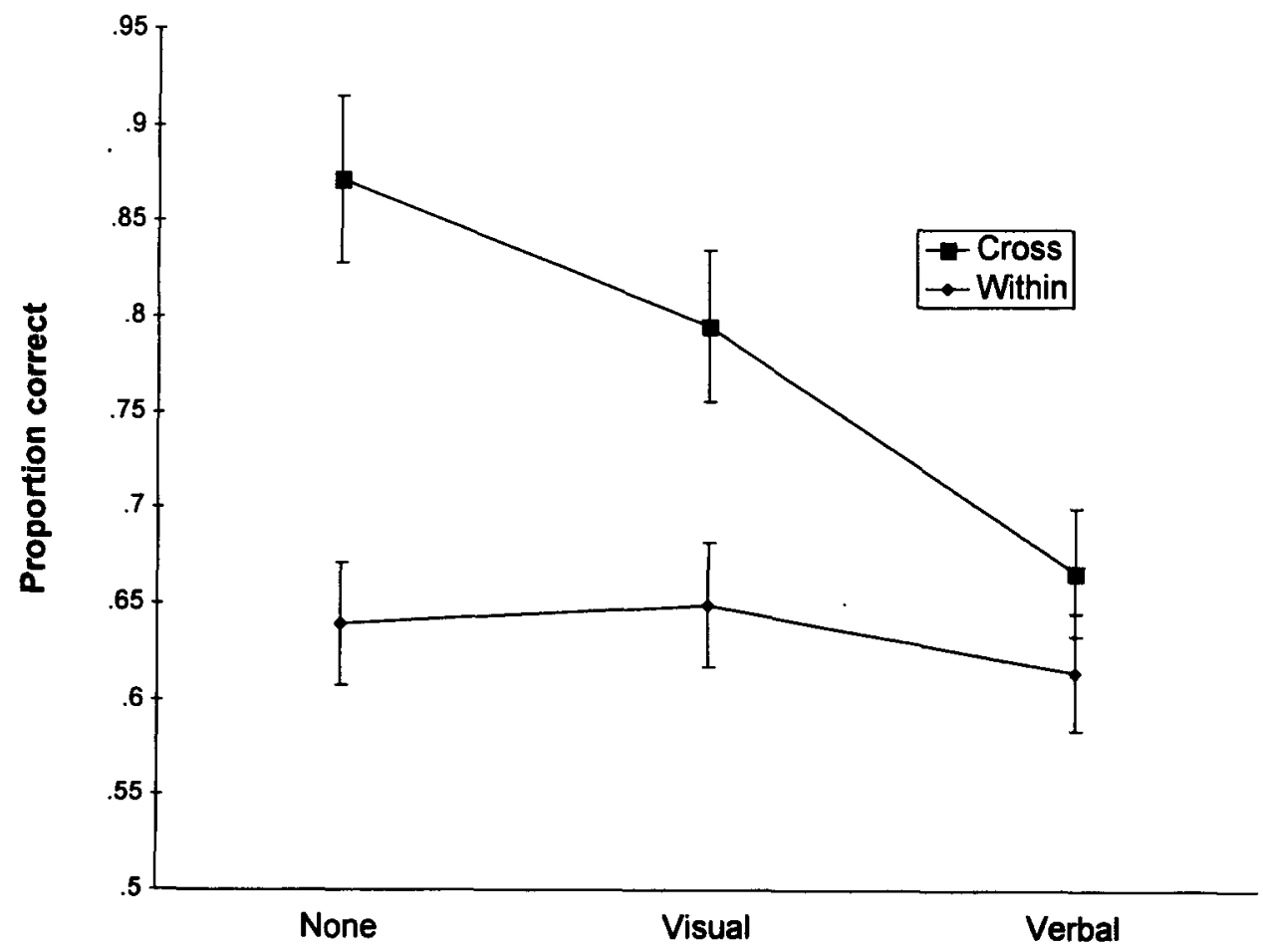

Figure 5. Mean proportion of correct identifications in Experiment 5 for cross- versus within-category pairs of faces with no, visual, or verbal interference.

give chance performance; three-step pairs gave ceiling-level performance. So, Experiment 5 used only two-step pairs.

Procedure. The procedure was basically the same as for Experiment 2; it investigated three types of interference condition (none, visual, and verbal). Longer exposure times $(1,250 \mathrm{msec})$ were used for the test stimuli and a pilot study showed that a 10 -sec delay was needed between target and test stimuli to avoid ceiling effects.

For each condition, each subject saw two within-category pairs and two cross-category pairs. There were eight repetitions of each pair in each condition, giving 32 trials/condition and 96 trials in all The interference consisted of face-like features in the visual condition and adjectives describing facial expressions in the verbal condition, but avoiding adjectives referring to happy, fearful, or angry faces.

\section{Results}

The proportion of mean accuracy scores was analyzed in a 3 (interference type: none vs. visual vs. verbal) $\times 2$ (pair type: cross- vs. within-category) ANOVA with repeated measures over both factors. There was a significant effect of interference $\left[F(2,46)=5.06, M S_{\mathrm{e}}=.03\right.$, $p<.05]$, a significant effect of pair type $[F(1,23)=$ $\left.82.04, M S_{\mathrm{e}}=.01, p<.001\right]$, and a significant interaction $\left[F(2,46)=7.0, M S_{\mathrm{e}}=.01, p<.01\right]$.

An examination of the interaction with Newman-Keuls pairwise comparisons showed that, while there was no difference between the conditions for within-category pairs, for cross-category pairs significantly more targets were correctly identified with no interference $(p<.01)$ and visual interference $(p<.05)$ than with verbal interference. While the difference between cross- and within- category words was significant with no interference $(p<$ $.01)$ and with visual interference $(p<.01)$, it was not significant with verbal interference. Figure 5 illustrates these results.

\section{Discussion}

Once more, the advantage for cross-category pairs has been completely removed by verbal interference. However, in Experiment 5, visual interference was not found to be significantly effective in lowering performance levels. We, of course, cannot conclude from these results with visual interference that the recognition of facial expression does not require visual coding; this would be an inappropriate conclusion from a null result. It is more likely that our visual interference was not sufficiently similar to the targets to disrupt performance. Our interference material did not selectively involve facial expressions, and it has been argued that facial expressions require different coding from that used for facial identity (Etcoff, 1984).

\section{GENERAL DISCUSSION}

Until recently (Davidoff, Davies, \& Roberson, 1999), both anthropological and psychological studies had provided converging evidence for universal systems of color categorization and facial expression categorization. The visible spectrum varies, according to Berlin and Kay (1969), continuously along a continuum yet is divided into 
a relatively small number of fairly fixed color categories found in most cultures. A similarly small but universally fixed number of facial expressions has also been proposed (Ekman, 1992). Hence, categorical perception could also be universal; indeed, it has been reported in the very young child (Bornstein, Kessen, \& Weiskopf, 1976). Fourmonth-old infants discriminated between categories in a way similar to adult subjects (Bornstein et al., 1976); this is far earlier than young children acquire lexical labels, and that age is even some time before they are able to correctly apply them (Andrick \& Tager-Flusberg, 1986). One would suppose, therefore, that perceptual categorization is inherent in the visual processing of the stimuli. Consequently, our present results may cause surprise when viewed from the universal perspective because they appear to show that the cross-category advantage relies on verbal coding.

In our studies, it is difficult to argue that the verbal interference tasks contained hidden visual-spatial aspects that disrupted categorical perception. Verbal interference selectively affected cross-category comparisons, and we would have to argue that the supposed visual-spatial aspects were not present in the ostensibly visual task that produced interference for all targets. However, it is easy to find a reason for the disappearance of categorical perception if it is based on verbal coding. While visual coding could be useful for finding targets from both crossand within-category pairs, verbal coding would not be at all useful for within-category pairs, since both members share the same name. Of course, for cross-category pairs, verbal coding could help to differentiate members of the test pair.

There is, of course, nothing new in an emphasis on verbal codes in memory, even for colors. Most famously, Loftus (1979) argued that subjects may integrate verbal information in such a way as to update (i.e., change) existing visual memories. However, there are two further reasons why our experimental procedures might have promoted verbal coding. The first reason is that, except for the baseline condition of Experiment 1, subjects had to maintain the memory of the color or face for at least $5 \mathrm{sec}$. Perhaps, in general, adult subjects require great incentives to ignore verbal codes when recognition memory is demanded over such intervals. Subjects may be intuitively aware that verbal rehearsal of a stimulus label generally improves subsequent memory performance even, under some conditions, for faces and pictures (Bartlett, Till, \& Levy, 1980; Read, 1979). The second reason for a dominance of verbal coding could be that subjects implicitly, and automatically, name stimuli if at all possible. Implicit naming has been argued to be the reason why the memory span for pictures of objects does not exceed that for their labels (Schiano \& Watkins, 1981).

Our results would seem to imply that categorical perception requires verbal codes and does not require visual codes. However, it is quite reasonable to suppose that, for other tasks, colors and facial expressions are represented with both visual and verbal codes (Davidoff \& Ostergaard, 1984; Schooler \& Engstler-Schooler, 1990). There is no need for the alternative codes to carry equal weight in every retrieval context. So, while we may have appeared to show in the present design that categorical perception was based on verbal codes, one should remain cautious about a claim that visual codes are not involved in any way. For example, it has been found that subjects may use verbal coding only at some cost. Research has shown that verbal codes can be detrimental to visual coding; verbal processing may reduce the amount of encoded visual information (Nelson \& Brooks, 1973) or interfere with the subjects' ability to use visual coding for faces (Schooler \& Engstler-Schooler, 1990). It would be for further studies to detail the conditions under which adults are able to show visually based categorical perception.

\section{REFERENCES}

ANDrick, G. R., \& TAGER-FlusberG, H. (1986). The acquisition of color terms. Journal of Child Language, 13, 119-134.

Bart lett, J. C., Till, R. E., \& Levy, J. C. (1980). Retrieval characteristics of complex pictures: Effects of verbal encoding. Journal of Verbal Learning \& Verbal Behavior, 19, 430-449.

BerLin, B., \& KaY, P. (1969). Basic terms: Their universality and evolution. Berkeley: University of California Press.

Bornstein, M. H., Kessen, W., \& Weiskopf, S. (1976). Color vision and hue categorization in young human infants. Journal of Experimental Psychology: Human Perception \& Performance, 2, 115-129.

Bornstein, M. H., \& Korda, N. O. (1984). Discrimination and matching within and between hues measured by reaction times: Some implications for categorical perception and levels of information processing. Psychological Research, 46, 207-222.

Bourke, P. A., Duncan, J., \& Nimmo-Smith, I. (1996). A general factor involved in dual-task performance decrement. Quarterly Journal of Experimental Psychology, 49A, 525-545.

Brown, R. W., \& LenNeberG, E. H. (1954). A study in language and cognition. Journal of Abnormal \& Social Psychology, 49, 454-462.

Calder, A. J., Young, A. W., Perrett, D. I., Etcoff, N. L., \& RowLAND, D. (1996). Categorical perception of morphed facial expressions. Visual Cognition, 3, 81-117.

Carroll, J. B., Davies, P., \& Richman, B. (1971). Word frequency book. New York: American Heritage.

Davidoff, J., Davies, I. R. L., \& Roberson, D. (1999). Is colour categorisation universal? New evidence from a stone-age culture. Nature, 398, 203-204.

DAvidOFF, J., \& OstergaARD, A. L. (1984). Colour anomia resulting from weakened short-term colour memory. Brain, 107, 415-431.

Ekman, P. (1992). Facial expressions of emotion: An old controversy and new findings. Philosophical Transactions of the Royal Society of London: Series B, 335, 63-69.

Etcoff, N. L. (1984). Selective attention to facial identity and facial emotion. Neuropsychologia, 22, 281-295.

Etcoff, N. L., \& MAGEE. J. J. (1992). Categorical perception of facial expressions. Cognition, 44, 227-240.

Fletcher, R. (1980). The City University colour vision test. Windsor, U.K.: Keeler.

Goldstone, R. (1994). The role of similarity in categorisation: Providing a framework. Cognition, 52, 125-157.

Harnad, S. (1987). Psychophysical and cognitive aspects of categorical perception: A critical overview. In S. Harnad (Ed.), Categorical perception: The groundwork of cognition. Cambridge: Cambridge University Press.

IsHIHARA, S. (1992). Ishihara's tests for colour-blindness. Tokyo: Kanehara.

LofTus, E. F. (1979). Eyewitness testimony. Cambridge, MA: Harvard University Press.

Mulligan, N. W. (1999). The effects of perceptual interference at encoding on organization and order: Investigating the roles of itemspecific and relational information. Journal of Experimental Psychology: Learning. Memorv, \& Cognition, 25, 54-69. 
Nelson, D. L., \& Brooks, D. H. (1973). Functional independence of pictures and their verbal memory codes. Journal of Experimental Psychology, 98, 44-48.

READ, J. D. (1979). Rehearsal and recognition of human faces. American Journal of Psychology, 92, 71-85.

RoBerson, D., DavidofF, J., \& BraisBy, N. (1999). Similarity and categorisation: Neuropsychological evidence for a dissociation in explicit categorisation tasks. Cognition, 71, 1-42.
Schiano, D. J., \& Watkins, M. J. (1981). Speech-like coding of pictures in short-term memory. Memory \& Cognition, 9, 110-114.

SCHOOLER, J. W., \& ENGSTLER-SCHOOLER, T. Y. (1990). Verbal overshadowing of visual memories: Some things are better left unsaid. Cognitive Psychology, 22, 36-71.

Young, A. W., Rowland, D., Calder, A. J., Etcoff, N. L., Seth, A., \& Perrett, D. I. (1997). Facial expresion megamix: Tests of dimensional and category accounts of emotion recognition. Cognition, 63, 271-313.

\begin{tabular}{llll}
\multicolumn{4}{c}{$\begin{array}{c}\text { APPENDIX A } \\
\text { List of Words Used as Verbal Interference } \\
\text { in Experiment 1 }\end{array}$} \\
\hline BEIGE & KHAKI & PEACH & FAWN \\
TAN & CREAM & PEARL & OLIVE \\
NAVY & CHERRY & OLIVE & PEARL \\
KHAKI & MAUVE & FAWN & CHERRY \\
TAN & OLIVE & BUFF & NAVY \\
PEARL & PEACH & BEIGE & MAUVE \\
CHERRY & PEARL & CREAM & PEACH \\
BUFF & KHAKI & TAN & FAWN \\
\hline
\end{tabular}

APPENDIX B

Tristimulus Coordinates for the 12 Computer-Generated Munsell Colors Used in Experiment 2

\begin{tabular}{cccc}
\multicolumn{4}{c}{ Munsell Colors Used in Experiment 2} \\
\hline Munsell Denomination & $Y$ & $x$ & $y$ \\
\hline 7.5 B 6/5 & 8.6 & .248 & .279 \\
3.75 B 6/5 & 9.9 & .244 & .291 \\
2.5 B 6/5 & 10.8 & .244 & .295 \\
1.25 B 6/5 & 10.2 & .246 & .305 \\
10 BG 6/5 & 8.55 & .246 & .306 \\
8.75 BG 6/5 & 10.1 & .247 & .312 \\
6.25 BG 6/5 & 10.7 & .252 & .322 \\
5 BG 6/5 & 9.74 & .254 & .328 \\
3.75 BG 6/5 & 8.73 & .258 & .334 \\
2.5 BG 6/5 & 10.1 & .260 & .341 \\
1.25 BG 6/5 & 10.6 & .204 & .355 \\
7.5 G 6/5 & 9.63 & .274 & .360 \\
\hline
\end{tabular}

\begin{tabular}{llll}
\multicolumn{4}{c}{$\begin{array}{c}\text { APPENDIX C } \\
\text { List of Words Used as Verbal Interference } \\
\text { in Experiment } 3\end{array}$} \\
\hline BEECH & TOSS & RITE & FOIL \\
PEGS & SINKS & WAXED & LASH \\
MICE & CROWNED & LAPSE & TACT \\
LAIN & NIP & KALE & LASH \\
SCRIPT & TOSS & HEN & RITE \\
CRACKED & KALE & DANCED & NIP \\
LAPSE & BEECH & HEN & TOSS \\
FOIL & DANCED & LASH & PEGS \\
\hline
\end{tabular}

(Manuscript received May 12, 1998

revision accepted for publication October 18, 1999.) 